\title{
Resistência s Antimicrobianos de Bactérias Gram Negativas Isoladas de Leite Orgânico e Leite Não Orgânico Comercializados Na Zona Sul do Rio de Janeiro
}

\author{
Beatriz Clarissa dos Santos Ferreira e Pereira (I), Janaína dos \\ Santos Nascimento (I), Leonardo Emanuel de Oliveira Costa (I) \\ (I) IFRJ - Instituto Federal de Educação do Rio de Janeiro (Rua Senador Furtado, 121, \\ Maracanã. Rio de Janeiro/RJ, Brasil. CEP: 20270-021)
}

\section{Resumo}

O leite é o produto de origem animal mais consumido pela população brasileira, especialmente por crianças e idosos, porém, segundo o Programa de Análise de Resíduos de Medicamentos Veterinários em Alimentos de Origem Animal (Pamvet) a presença de resíduos de antimicrobianos é comum, tornando o produto impróprio para o consumo humano. Aliado a este fato, cresce a cada ano a procura por alimentos de boa qualidade e valor nutricional. Em resposta a esta nova demanda do consumidor, introduziu-se no mercado os alimentos orgânicos que são considerados de melhor qualidade nutricional. Desta forma, objetivou-se com este trabalho identificar os isolados obtidos previamente em exames de qualidade microbiológica de leite orgânico e não orgânico e caracterizar a resistência aos antimicrobianos destas bactérias. Neste estudo foram analisadas 26 e 29 bactérias gram negativas isoladas respectivamente de leite orgânico e não orgânico, comercializados em estabelecimentos da Zona Sul da Cidade do Rio de Janeiro/Brasil que foram obtidas previamente na análise de qualidade microbiológica de 18 amostras de leite coletadas nos Bairros de Botafogo e Laranjeiras. Os isolados foram submetidos ao teste de oxidase e após foram identificados utilizando-se os Kits Bactray I, II e III (laborclin ${ }^{\circledR}$ ). O antibiograma foi realizado segundo as normas do Clinical and Laboratory Standards Institute (CLSI). Entre as espécies identificadas

\footnotetext{
Referência:

Beatriz Clarissa dos Santos Ferreira e Pereira, Janaína dos Santos Nascimento, Leonardo Emanuel de Oliveira Costa. Resistência A Antimicrobianos de Bactérias Gram Negativas Isoladas de Leite Orgânico e Leite Não Orgânico Comercializados Na Zona Sul do Rio de Janeiro. In: Anais do 12 Congresso Latinoamericano de Microbiologia e Higiene de Alimentos - MICROAL 2014 [= Blucher Food Science Proceedings, num.1, vol.1]. São Paulo: Editora Blucher, 2014. 
destacamos as bactérias psicotróficas Acinetobacter sp., que apresentou maior frequência tanto em leite orgânico como em leite não orgânico, e Pseudomonas aeruginosa que foi obtida apenas de leite não orgânico. Entre as enterobactérias isoladas destacam-se: Klebsiella pneumoniae, Enterobacter cloacae e Escherichia coli. O teste de antibiograma dos isolados obtidos a partir de leite orgânico mostrou que: 15,4\% foram intermediários ao imipenem, 34,6\% dos isolados apresentaram resistência a tetraciclina, 15,4\% apresentaram resistência a ampicilina e 3,8\% foram resistentes a ceftazidima, cefotaxima, cloranfenicol e amicacina. $\mathrm{O}$ teste de antibiograma dos isolados obtidos a partir de leite não orgânico mostrou que: $17,2 \%$ foram intermediários ao imipenem, 3,4\% dos isolados apresentaram resistência a tetraciclina, ceftazidima, cefotaxima, ampicilina e amicacina. A presença de várias bactérias resistentes no leite orgânico não era esperada, visto que, na produção dos produtos orgânicos de origem animal, não é permitido o uso de antibióticos para tratamento dos animais.

Palavras-Chave: Acinetobacter sp., antibiograma, leite, orgânico, Pseudomonas aeruginosa

Agência de Fomento: IFRJ, FAPERJ 